\title{
Ultrasound-guided Bedside Core Needle Biopsy: A Hospitalist Procedure Team's Experience
}

\author{
Sanjay A. Patel ${ }^{1}$, Krzysztof Pierko $^{1}$, Ricardo Franco-Sadud ${ }^{2}$ \\ 1. Internal Medicine, John H. Stroger, Jr. Hospital of Cook County, Chicago, USA 2. Internal Medicine, NCH Healthcare \\ System, Naples, USA
}

Corresponding author: Sanjay A. Patel, sanjay.a.patel@gmail.com

\begin{abstract}
Tissue pathology is integral for the diagnosis of various conditions, especially malignancy. Traditionally, biopsy procedures, including core needle biopsy (CNB), are performed by surgeons or radiologists. With the increasing utilization of point of care ultrasound (POCUS) skills and competence in bedside procedures by general internists, CNB can be safely moved to the patient's bedside with maintained accuracy and increased cost savings compared to traditional procedural methods. We aim to review the experience of our hospitalist-run medical procedure service in performing these ultrasound-guided procedures at the bedside.
\end{abstract}

Categories: Internal Medicine, Pathology, Oncology

Keywords: core biopsy, needle biopsy, cost savings, bedside procedures, point of care ultrasound

\section{Introduction}

Biopsy of a nodule, mass or lymph node is the gold standard for diagnosis of a variety of conditions, especially malignancy. Tissue sampling can be done via one of three methods-fine needle aspiration (FNA), core needle biopsy (CNB) or open surgical biopsy. Choosing a method is dependent upon the suspected pathology, procedural safety, patient factors and preference. FNA and CNB allow for less invasive procedures, lesser healthcare costs and shorter recovery times [1-3]. Pathology from open biopsy has historically provided better diagnostic yield, but FNA and CNB have gained traction as reasonable alternatives without sacrificing diagnostic outcomes [1,4-7]. Across a range of pathologies, the yield of CNB (81-95\% sensitivity, 80-100\% specificity, 93-95\% accuracy) compared to FNA (63-80\% sensitivity, 70-80\% specificity, $80 \%$ accuracy) has made it a more preferable initial test of choice [8-10]. CNB is less prone to sampling errors and allows for better characterization of the target lesion compared to FNA, often requiring less follow-up procedures $[5,11,12]$. The addition of procedural ultrasound guidance provides safety benefit along with characterization of target lesions, contributing more pre-procedural bedside clinical information than other biopsy modalities $[13,14]$.

Received 12/11/2018 Review began 12/13/2018 Review ended 12/26/2018 Published 01/03/2019

๑) Copyright 2019 Patel et al. This is an open access article distributed under the terms of the Creative Commons Attribution License CC-BY 3.0., which permits unrestricted use, distribution, and reproduction in any medium, provided the original author and source are credited.
Biopsy procedures have historically been a duty of surgeons, radiologists and subspecialists. They are usually performed in special procedure rooms, interventional radiology suites or operating rooms. Along with physical location comes the added costs and resources of nursing staff, procedural sedation and monitoring, transportation and equipment. Meanwhile, general internists, particularly hospitalists, are increasingly becoming familiar and competent with bedside procedures $[15,16]$. Combined with the advent of hospitalist-run bedside procedure services across the nation, a growing interest has sprouted in ultrasound-guided bedside procedures [17,18]. Ultrasound machines have become more portable over time and the skillset of the general internist has increased accordingly. This combination aims to increase healthcare efficiency while decreasing overall cost. A growing body of literature supports the safety of needle biopsy being done at the bedside with sonographic guidance [19]. Training for these procedures can be incorporated as part of the instruction and development curriculum for a variety of other bedside procedures and point-of-care ultrasound applications.

CNB is not typically within the scope of existing bedside procedure teams. We aim here to review our team's pilot experience in a large urban safety-net tertiary center. Particular interest is focused on technical safety, cost savings and future lessons for improvement in performing bedside ultrasound-guided biopsies by general internists.

\section{Materials And Methods}

Our medical procedure service (MPS) is comprised of five attending hospitalists (proceduralists) and one nurse clinician trained in point-of-care ultrasound and basic bedside medical procedures (paracentesis, thoracentesis, lumbar puncture and vascular access). Since its inception in 2006, an average of 2200 procedures are completed yearly. All procedures are requested via computerized physician order entry to allow accurate record keeping of performance and quality measures.

From January, 2015 to June, 2017, the MPS received 73 requests for bedside CNB. Based upon patient factors, 


\section{Cureus}

equipment availability, lesion size and provider logistics, 60 biopsies have been performed. Over this time, three faculty self-volunteered to train and perform these procedures along with lymph node ultrasound, with two of those three faculty performing the majority $(55 / 60,92 \%)$ of the procedures. Thirty-five biopsies were performed with a 14-gauge, automatic spring-loaded biopsy device. The remaining 25 biopsies were performed with an 18-gauge device. The decision of core needle size was left solely to the provider based upon lesion size or availability of equipment. All procedures were done with sterile equipment and technique, and all were performed with dynamic real-time ultrasound guidance using local anesthesia alone.

The sole eligibility criteria for the consideration of a biopsy was that a lesion be superficial and either readily palpable or visible to the physician. The decision to move forward with a CNB request was dependent upon the proceduralist's comfort with dynamic ultrasound imaging of the lesion. Reasons not to perform the procedure included inadequate lesion size, safety concerns (Figure 1), lack of appropriate equipment or patient refusal. The excluded requests were referred to the appropriate subspecialist for consideration.

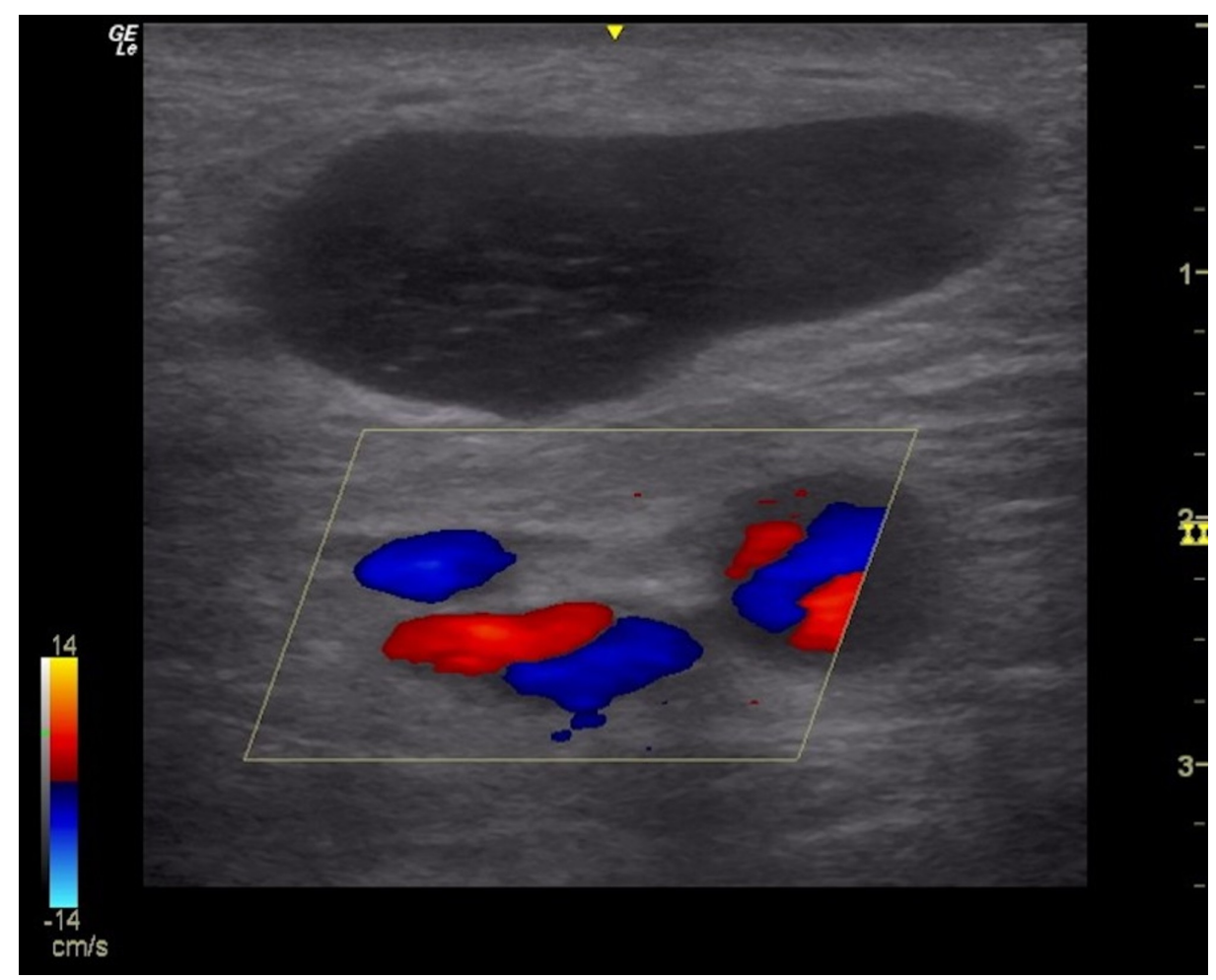

FIGURE 1: Metastatic lymph node with surrounding vasculature.

\section{Results}

The total number of samples obtained was 197 over 60 biopsies, an average of 3.3 samples per procedure (Table 1). The average size of lesions was $3.3 \mathrm{~cm}$, with a range of 1.5 to $10 \mathrm{~cm}$. Eighty-three percent (50/60) of the biopsies were performed on the same day, with an average request-to-procedure time of 3.5 hours. The remaining 10 were done the next working day, with the reason for delay in all cases being that the procedure was requested late in the day or over a weekend. The pathology submitted from all biopsies yielded an initial definitive diagnosis in all but four cases. All four cases $(4 / 60,6.7 \%)$ had an initial histologic diagnosis of reactive adenopathy. Follow-up excisional biopsy in all cases, driven by clinical suspicion for malignancy, supported the initial CNB pathology. This correlated to an actionable diagnostic yield of $93.3 \%$, similar to reported literature [7-9,11]. Considering the final excisional biopsy results of the aforementioned four procedures, the retrospective diagnostic accuracy of bedside biopsies was $100 \%$.

All but $21.7 \%$ (13/60) of cases returned a diagnosis of malignancy. Four demonstrated reactive adenopathy as discussed already. Of the remaining eight cases, one revealed non-caseating granulomas and lymphadenitis (final diagnosis of sarcoidosis was made based upon clinical presentation and pathology). Another four revealed caseating granulomas where the final diagnosis of tuberculous lymphadenitis was made. Two cases revealed a benign tumor-a fibrous histiocytoma and a lipoma. One case revealed a dense methicillin-resistant staphylococcus aureus (MRSA) panniculitis that was treated successfully with antibiotic therapy. The final case revealed actinomycosis, treated successfully with antibiotics upon identification from tissue culture. 
diagnosis of cancer. Of this total, 24/47 (51\%) were of the hematologic variety and 23/47 (49\%) were of the solid tumor variety. None of these cases required subsequent nodal tissue sampling as enough information was obtained from the CNB for definitive diagnosis. The most common of these diagnoses was non-Hodgkin lymphoma. Of the solid malignancies, the pathologies ranged across a spectrum of tumor types (Table 1 ).

\begin{tabular}{|c|c|c|}
\hline Non-Malignant ( $n=13)$ & Hematologic Malignancy $(n=24)$ & Solid Tumor Malignancy $(n=23)$ \\
\hline Actinomycosis (1) & Chronic Lymphocytic Leukemia (1) & Colorectal Adenocarcinoma (3) \\
\hline Fibrous Histiocytoma (1) & Hodgkin Lymphoma (2) & Gynecologic Adenocarcinoma (4) \\
\hline Lipoma (1) & Non-Hodgkın Lymphoma (15) & Head \& Neck Squamous Cell (2) \\
\hline Sarcoidosis (1) & Plasmacytoma (2) & Lung Adenocarcinoma (4) \\
\hline Tuberculosis (4) & T-Cell Lymphoma (3) & Lung Squamous Cell (4) \\
\hline Panniculitis (1) & & Lung Small Cell (1) \\
\hline \multirow[t]{4}{*}{ Reactive Lymphadenopathy (4) } & & Papillary Thyroid (1) \\
\hline & & Prostate Adenocarcinoma (2) \\
\hline & & Spindle Cell Carcinoma (1) \\
\hline & & Poorly Differentiated Adenocarcinoma (1) \\
\hline
\end{tabular}

TABLE 1: Diagnosis by pathology $(n=60)$.

One minor complication occurred in the group. A patient, who was on dual-antiplatelet therapy, had mild bleeding $(20 \mathrm{ml})$ from the puncture site that resolved within minutes following application of direct pressure. This accounted for $1.7 \%(1 / 60)$ of the patient cohort, similar to described rates of hemorrhage in the literature-the most well-described procedural risk [7,19,20]. Post-procedural ultrasonography did not reveal any evidence of hematoma. The overall group had average normal coagulation and hematologic parameters.

\section{Discussion}

CNB of superficial lesions, in particular lymph nodes, at the bedside is a promising alternative to traditional CNB performed by subspecialists or traditional open biopsy procedures. In our patient review, diagnostic accuracy is comparable, if not better, to that already described in the literature $[8,10,16]$. Though our model exclusively examined inpatients, we believe there is generalizability to the outpatient setting-whereby costs, time-to-diagnosis and specialty referrals could further decrease. Similar to renal and liver biopsy, bedside CNB of superficial lesions with sonographic localization is a skill that is learnable $[19,21,22]$. Training time is minimal compared to open biopsy methods, with the advantage of increased convenience, decreased cost and improved healthcare efficiency-all while maintaining similar rates of diagnostic accuracy and complication rates. Bedside CNB with ultrasound guidance should be incorporated into the general internist's armament of diagnostic testing.

While our study demonstrates many advantages, we recognize certain limitations. Prerequisite for biopsy consideration was that the lesion be readily visible or palpable. Assuredly, this introduced a selection bias, with the likelihood of obtaining successful tissue with minimal complications being higher with larger and more superficial lesions $[23,24]$. However, this frame of thinking could apply to any specialist-performed procedure, including interventional radiology or surgery. An essential element of moving forward with any procedure, including CNB, is the technical feasibility of that procedure. It naturally follows that the more feasible a procedure is, the more successful-in this case measured by accuracy and complications. It would likewise be naive to ignore how the experience of the provider would play into the technical aspects of the procedure. We propose that utilizing $\mathrm{CNB}$ at the bedside be reserved for more readily accessible lesions, at least initially. Better-defined roles and responsibilities between specialists and general internists are needed.

Training required, though minimal, may also be a limiting factor in broader implementation of bedside CNB by general internists. One potential limiting factor is accessibility to ultrasound, which is institutionspecific. In our example above, the procedures were carried out by trained proceduralists who are staff in inpatient MPS. They readily have access to an ultrasound machine for imaging guidance that was of no added overall capital cost. If not readily available, institutional purchase of an inexpensive point-of-care ultrasound machine may be of interest, especially with increasing popularity of imaging-guided procedures 
and point-of-care ultrasound applications. Universally defining procedural competency has been historically deficient, and assessing expertise may be difficult [25]. Evaluation processes have been proposed for other high-volume procedures performed by internists-including central line insertion, lumbar puncture, thoracentesis and paracentesis. Guidelines are also anticipated soon from the Society of Hospital Medicine on training and credentialing in such procedures and point of care ultrasonography by hospitalists $[26,27]$. Yet, for bedside ultrasound-guided CNB, no such defined training parameters exist. Additional operator bias was likely present, being that the proceduralists were self-selected and likely to be skilled operators compared to any non-procedure oriented physician.

Although we did not discreetly measure cost savings, we presume there to be a significant decrease in patient and hospital costs for such provided services. A reduced need for patient transport, consultations for the sake of a procedure may impact the length of hospital stay-especially provided biopsies can be performed on the same day as in our model. As mentioned, nearly $75 \%$ of biopsies were done on the same day they were requested which assisted in hospital throughput. Assuming costs hold true from existing data of other procedures moved to the bedside, i.e. peripherally inserted central catheter (PICC), a minimum cost of the radiology suite (range $\$ 300-2000$ ) can be saved [28,29]. Multiplied across our procedures would have saved between $\$ 18,000$ and $\$ 120,000$. This is a conservative estimate, excluding potential savings from the length of stay, transportation, nursing staff and equipment and medication costs. Across a range of institutions, this figure could presumably balloon into the hundreds of thousands of dollars when applied to the United States healthcare system. We theorize that by performing biopsies as an inpatient, we also decreased the time to diagnosis and prevented delays in outpatient referrals and treatment. Patient satisfaction with a bedside CNB, similar to other procedures, may also be preferable, but directly unmeasured [30].

\section{Conclusions}

Bedside CNB by internists is a safe and effective alternative to traditional open biopsy procedures and specialist performed CNB. As evidenced by the series described above, it is learnable by a variety of physicians across healthcare specialties. The likeliest benefit is for general medical services-including, but not limited to, pediatrics, internal medicine, hospital medicine and family medicine providers. With the growing use and interest in bedside ultrasound, an equally growing interest and use of CNB can be justified to improve healthcare efficiency and cost. Ultrasound-guided CNB can be added to armament of skills available to internists. A definitive cost assessment is needed along with a standardized training model. In conclusion, we believe moving these procedures to the bedside by internists would improve the overall delivery of care to patients.

\section{Additional Information}

\section{Disclosures}

Human subjects: Consent was obtained by all participants in this study. Cook County Health \& Hospitals System Institutional Review Board issued approval 16-053. Dear Dr. Patel, Your study entitled "Bedside Core Biopsies" has received expedited review approval on 4/15/2017. The study period will remain open for 1 year prior to closure, after which no further data may be collected unless a progress report or amendment is submitted. Upon completion of study, please submit final report to IRB committee. Betty Donoval. Animal subjects: All authors have confirmed that this study did not involve animal subjects or tissue. Conflicts of interest: In compliance with the ICMJE uniform disclosure form, all authors declare the following: Payment/services info: All authors have declared that no financial support was received from any organization for the submitted work. Financial relationships: All authors have declared that they have no financial relationships at present or within the previous three years with any organizations that might have an interest in the submitted work. Other relationships: All authors have declared that there are no other relationships or activities that could appear to have influenced the submitted work.

\section{Acknowledgements}

We thank the Interventional Radiology department at John H. Stroger, Jr. Hospital of Cook County for their assistance in piloting this initiative, particulary Drs. Thomas Gast and Daniel Kay.

\section{References}

1. Skrzynski MC, Biermann JS, Montag A, Simon MA: Diagnostic accuracy and charge-savings of outpatient core needle biopsy compared with open biopsy of musculoskeletal tumors. J Bone Joint Surg. 1996, 78:644649. 10.2106/00004623-199605000-00002

2. Liberman L, Feng TL, Dershaw DD, Morris EA, Abramson AF: US-guided core breast biopsy: use and costeffectiveness. Radiology. 1998, 208:717-723. 10.1148/radiology.208.3.9722851

3. Burkhardt JH, Sunshine JH: Core-needle and surgical breast biopsy: comparison of three methods of assessing cost. Radiology. 1999, 212:181-188. 10.1148/radiology.212.1.r99j146181

4. Bruening W, Fontanarosa J, Tipton K, Treadwell JR, Launders J, Schoelles K: Systematic review: comparative effectiveness of core-needle and open surgical biopsy to diagnose breast lesions. Ann Intern Med. 2010, 152:238-246. 10.7326/0003-4819-152-1-201001050-00190

5. Lachar WA, Shahab I, Saad AJ: Accuracy and cost-effectiveness of core needle biopsy in the evaluation of 
suspected lymphoma: a study of 101 cases. Arch Pathol Lab Med. 2007, 131:1033-1039. 10.1043/15432165(2007)131[1033:AACOCN]2.0.CO;2

6. Zinzani PL, Colecchia A, Festi D, et al.: Ultrasound-guided core-needle biopsy is effective in the initial diagnosis of lymphoma patients. Haematologica. 1998, 83:989-992.

7. Kasraeian S, Allison DC, Ahlmann ER, Fedenko AN, Menendez LR: A comparison of fine-needle aspiration, core biopsy, and surgical biopsy in the diagnosis of extremity soft tissue masses. Clin Orthop Relat Res. 2010, 468:2992-3002. 10.1007/s11999-010-1401-x

8. Dupuy DE, Rosenberg AE, Punyaratabadhu T, Tan MH, Mankin HJ: Accuracy of CT-guided needle biopsy of musculoskeletal neoplasms. Am J Roentgenol. 1998, 171:759-762. 10.2214/ajr.171.3.ajronline_171_3_001

9. Ganott MA, Zuley ML, Abrams GS, et al.: Ultrasound guided core biopsy versus fine needle aspiration for evaluation of axillary lymphadenopathy in patients with breast cancer. ISRN Oncol. 2014, 2014:9. Accessed: August 1, 2017: https://www.hindawi.com/journals/isrn/2014/703160/. 10.1155/2014/703160

10. Orell SR: Pitfalls in fine needle aspiration cytology . Cytopathology. 2003, 14:173-182. 10.1046/j.13652303.2003.00078.x

11. Rautianen S, Masarwah A, Sudah M, et al.: Axillary lymph node biopsy in newly diagnosed breast cancer: comparative accuracy of fine-needle aspiration biopsy versus core-needle biopsy. Radiology. 2013, 269:5460. 10.1148/radiol.13122637

12. Ahuja AT, Ying M, Ho SY, Antonio G, Lee YP, King AD, Wong KT: Ultrasound of malignant cervical lymph nodes. Cancer Imaging. 2008, 8:48-56. 10.1102/1470-7330.2008.0006

13. Sumi M, Ohki M, Nakamura T: Comparison of sonography and CT for differentiating benign from malignant cervical lymph nodes in patients with squamous cell carcinoma of the head and neck. AJR Am J Roentgenol. 2001, 176:1019-1024. 10.2214/ajr.176.4.1761019

14. Soni NJ, Lucas BP: Diagnostic point-of-care ultrasound for hospitalists. J Hosp Med. 2015, 10:120-124. 10.1002/jhm.2285

15. Bhagra A, Tierney D, Sekiguchi H, Soni NJ: Point-of-care ultrasonography for primary care physicians and general internists. Mayo Clin Proc. 2016, 91:1811-1827. 10.1016/j.mayocp.2016.08.023

16. Franco-Sadud R, Dancel R, Schnobrich D, Tierney D, Puri N, Soni N: Hospitalist procedure services. SGIM Forum. 2016, 39:13-15.

17. Lucas BP, Asbury JK, Wang Y, et al.: Impact of a bedside procedure service on general medicine inpatients: a firm-based trial. J Hosp Med. 2007, 2:143-149. 10.1002/jhm.159

18. Nass K, O’Neill WC: Bedside renal biopsy: ultrasound guidance by the nephrologist. Am J Kidney Dis. 1999, 34:955-959. 10.1016/S0272-6386(99)70058-2

19. He Y, Ji X, Xie Y, He B, Xu X, Chen X, Zhang Q: Clinical application of ultrasound-guided core needle biopsy with multiple punches in the diagnosis of lymphoma. World J Surg Oncol. 2015, 13:126. 10.1186/s12957015-0537-2

20. Gupta S, Wallace MJ, Cardella JF, Kundu S, Miller DL, Rose SC: Quality improvement guidelines for percutaneous needle biopsy. J Vasc Interv Radiol. 2010, 21:969-975. 10.1016/j.jvir.2010.01.011

21. Chung S, Koh ES, Kim SI, Yoon HE, Park CW, Chang YS, Shin SI: Safety and tissue yield for percutaneous native kidney biopsy according to practitioner and ultrasound technique. BMC Nephrol. 2014, 15:96. Accessed: July 21, 2017: https://bmcnephrol.biomedcentral.com/articles/10.1186/1471-2369-15-96. 10.1186/1471-2369-15-96

22. Gunneson TJ, Menon KV, Wiesner RH, et al.: Ultrasound-assisted percutaneous liver biopsy performed by a physician assistant. Am J Gastroenterol. 2002, 97:1472-1475. 10.1111/j.1572-0241.2002.05789.x

23. Huang PC, Liu CY, Chuang WY, Shih LY, Wan YL: Ultrasound-guided core needle biopsy of cervical lymphadenopathy in patients with lymphoma: the clinical efficacy and factors associated with unsuccessful diagnosis. Ultrasound Med Biol. 2010, 36:1431-1436. 10.1016/j.ultrasmedbio.2010.05.018

24. Kim BM, Kim EK, Kim MJ, Yang WI, Park CS, Park SI: Sonographically guided core needle biopsy of cervical lymphadenopathy in patients without known malignancy. J Ultrasound Med. 2007, 26:585-591. 10.7863/jum.2007.26.5.585

25. Lenchus JD, Carvalho CM, Ferreri K, Sanko JS, Arheart KL, Fitzpatrick M, Issenberg SB: Filling the void: defining invasive bedside procedural competency for internal medicine residents. J Grad Med Educ. 2013, 5:605-612. 10.4300/JGME-D-13-00030.1

26. Soni NJ, Tierney DM, Jensen TP, Lucas BP: Certification of point-of-care ultrasound competency. J Hosp Med. 2017, 12:775-776. 10.12788/jhm.2812

27. Lucas BP, Tierney DM, Jensen TP, et al.: Credentialing of hospitalists in ultrasound-guided bedside procedures: a position statement of the Society of Hospital Medicine. J Hosp Med. 2018, 13:126-135. 10.12788/jhm.2917

28. Hornsby S, Matter K, Beets B, Casey S, Kokotis K: Cost losses associated with the "PICC, stick, and run team" concept. J Infus Nurs. 2005, 28:45-53. 10.1097/00129804-200501000-00006

29. Davis J, Kokotis K: A new perspective for PICC line insertions: cost effectiveness and outcomes associated with an independent PICC service. J Assoc Vasc Access. 2004, 9:93-98. 10.2309/155288504774654955

30. Mourad M, Auerbach AD, Maselli J, Sliwka D: Patient satisfaction with a hospitalist procedure service: is bedside procedure teaching reassuring to patients?. J Hosp Med. 2011, 6:219-224. 10.1002/jhm.856 